\title{
THE EFFECTIVENESS OF USING THE EDUCOSOFT LEARNING MANAGEMENT SYSTEM TO TEACH MATH IN PUERTO RICO
}

\author{
Ángel M. Ojeda-Castro,Universidad del Turabo, Gurabo,PR, ut_aojeda@suagm.edu \\ Philip R. Murray-Finley, Universidad del Turabo, Gurabo,PR, pmurray2@suagm.edu \\ José Sánchez-Villafañe, Universidad del Turabo, Gurabo, PR, jsanchez@suagm.edu \\ Man M. Sharma, Professor Emeritus, Clark Atlanta University, GA, mms1948@aol.com \\ Ángel Rivera-Collazo, Universidad del Turabo,PR, arivera@suagm.edu
}

\begin{abstract}
The purpose of this study was to compare the effectiveness of the Educosoft Learning Management System (ELMS) with the traditional method of teaching math to first-year students who expect to continue studies in Health, Social Sciences, Design, Education, Business, Engineering, and Science and Technology at a private university in Puerto Rico. This was an experimental study designed for two groups, where a t test statistical analysis was used, with a 0.05 significance level. The subject population of the study was composed of 1,045 first-year college students, from which 491 were the control group and 550 were the experimental group. Students in the experimental group were exposed to the ELMS, while the students in the control group were taught the equivalent math course through the traditional classroom method. The course content for the control group was: Linear Equations, Linear Inequalities, Exponents, Polynomials and Scientific Notation. For the experimental group, the subjects covered were: Whole Numbers, Order of Operation, Fractions, Decimals, Percentages, Measurements, Linear Equations, Linear Inequalities, Exponents, Polynomials and Scientific Notation. The study found that teaching with the ELMS was more effective than the traditional teaching method in college-level mathematics.
\end{abstract}

Keywords: Learning Content Management System (LCMS), Learning Management Systems (LMS), Information Communication Technology (ICT), Educosoft Learning Management Systems (ELMS) and Puerto Rico.

\section{INTRODUCTION}

Unfortunately, many students entering universities are typically underprepared to meet the challenges of collegelevel mathematics. Consequently, many universities include remedial courses and tutoring services to help students attain the necessary skills to be successful in math. However, while the traditional approaches to teaching, learning, and tutoring have had some success, students in the American educational system still lag behind. For that reason, many educational institutions are actively seeking ways to improve student performance through innovative practices and technology. As the computer, software, and other technological advancements have become a part of daily life for many, the popularity of computer and Internet assisted instruction has also become a widespread global practice. The impact of the use of these innovative tools provides additional ways to facilitate teaching and learning experiences. As such, educators have also been urged to try new teaching strategies which utilize online, interdisciplinary collaborative learning, and the integration of statistical and math software in their courses [5, 7].

Today, universities are examining alternative approaches, such as the use of Computer Assisted Instruction to improve students' poor math skills. Usually, deficiencies in math skills begin in early education and continue through higher education. For decades, the academic performance of students in the mainland United States and Puerto Rico has been considerably lower than developed countries. This gap in achievement occurs in almost all disciplines; however, one of the greatest disparities occurs in the area of mathematics. Although the United States scores have improved slightly, they only ranks 32nd in the world among the most competitive nations, and only $6 \%$ achieve an advanced level in math [8]. Additionally, while deficiencies in math are consistent throughout the US, they are even more pronounced in Puerto Rican students. For example, the mean score of college-bound Puerto Rican students who took the SAT in 2010-2011 was only 452, while the mean score of all students who took the exam was 514 [23]. Unfortunately, this lack of achievement in math is more disheartening and widespread among many developing countries, like the island of Puerto Rico. By comparison, the Commonwealth of Puerto Rico has a 


\section{Issues in Information Systems}

Volume 14, Issue 2, pp.253-261, 2013

considerably lower rank in math when it is compared to the mainland United States. Half of the public students are not proficient in math [6]. Additionally, math scores on the College Entrance Examination Board (CEEB) have continued to decline during the last decade [6]. Consequently, educators are looking for ways to bridge the achievement gaps in mathematics. As such, some of the alternatives now being utilized are the use of the computer, software, Internet, and other educational technologies.

Educational technologies are changing the way in which education is delivered. Two significant changes are when and where students can take classes. Some of these technologies include e-learning environments and Learning Management Systems (LMS) which provide individualized and collaborative learning, an abundance of electronic resources and academic material from the Internet, software, and social networks [9]. The aforementioned have also been a catalyst for the growth of online education which allows students the opportunity to study in a non-traditional way. Students who find it difficult to study due to limited time, because of job and family responsibilities, commuting problems, distant geographic locations, or physical handicaps, have the ability to access their courses and academic programs at their convenience from a remote location [22]. Consequently, the roles of the teacher and student have also changed. Traditionally, teaching tasks take place in a classroom and the teacher controls all aspects of the learning experiences. Students in the traditional classroom receive explicit instructions, are guided through the process, and given feedback in a face-to-face environment. This type of traditional instruction is a more teacher-focused approach to learning, where the teacher makes all of the decisions. However, with new technology and virtual learning, the teacher's role has become one of facilitator rather than the absolute authority. As such, educators serve as guides and counselors in the modern school [5]. Therefore, if education is to provide an adequate preparation for the future, schools must empower the students to be more active and more responsible in organizing their own learning process [19]. Modern approaches motivate students to work more independently, with the liberty to determine their own goals, plan their own activities, and share their opinions with their instructors [20]. Additionally, they also aim to increase students' abilities to solve important real life problems [3].

Another significant change in e-learning is in the area of communication. Needless to mention, the success of the teaching-learning process is dependent upon the degree of integration and communication between the professor and the student [24]. Although communication is imperative in any learning environment, it is even more challenging in virtual environments. Most of the methodological difficulties stem from the fact that the traditional education face-to-face models cannot be applied directly to an e-learning environment [9]. Hence, Learning Management Systems must be more innovative to facilitate communication, student participation, and instructor feedback. However, this can be accomplished through synchronous and asynchronous activities such as emails, teleconferences, telephone calls, discussion forums, chat rooms, video-casts, podcasts, virtual whiteboards, and more.

In addition to the changes mentioned, the success of e-learning is dependent on several other factors. The information technology that includes computers and peripherals, software, Internet, and electronic multimedia are part of our existence in an increasing way. Therefore, it is necessary to integrate information technology in our curriculum [14]. However, integrating technology into the undergraduate math curriculum is a challenge and requires examining and confronting several issues [17]. Among those issues are curricular counseling, mandatory use, fairness of assessment, re-establishing goals, and developing technical knowledge of the teaching staff [17]. Undoubtedly, professors must improve their knowledge and skills in Information Computer Technology [20]. It is also essential to increase the use of the computer and technology in the classroom and laboratories [16]. Additionally, students need to be taught new skills in order to manage e-learning environments. This is because the new generation of cyber learners do not only have to confront the challenges of learning math content; they must also adapt to the learning material, learning a new technology, and understanding new methods of assessment and evaluation [12]. This is illustrated in the literature which mentions that students' knowledge in mathematics, technology, and the ability to integrate the technology, have a great impact on teaching and learning math in an online format $[10,11]$. 


\section{Issues in Information Systems \\ Volume 14, Issue 2, pp.253-261, 2013}

\section{Learning System}

There are several e-LMS or Learning Content Management Systems (LCMS) that are available and delivered through the Internet [2]. Some of the platforms widely used by universities in the world are Blackboard, Moodle and Sakai [9]. Some of these LMS have proprietor rights and are offered through a commercial license, while others are of open sources and are offered through a free public license (GNU Public License) [9]. Most of these platforms offer an excellent online teaching/learning experience and are easy to install, maintain, personalize and use [9]. They represent an exceptional resource for universities and schools to offer online courses and degrees [9]. These systems allow virtual implementation (online) on campuses where students, professors and administrators may gather and share information, and complete any academic activity such as registration, participation in discussion forums, delivery of course content, and the evaluation of students, professors and the course [9]. Using a LMS also facilitates the access to lectures, exercises, educational materials, comprehensive exams, online preparation, and activities among students and teachers synchronously or asynchronously [9].

One such LMS that is gaining recognition among mathematics educators is Educosoft. Educosoft integrates all aspects of math courses and may be used in conjunction with the traditional classroom as web-enhanced courses, blended format courses, or completely in a virtual environment as online courses. This platform was initially developed in 1985 with the help of the U.S. Department of Education and the IBM Corporation and was designed to be delivered off-line through local area networks. However, in 2001 Educosoft began to expand and converted its LMS content in virtual format. Figure 1 illustrates the home its home page. At present, Educosoft is used by students, professors and administrators in countries such as United States, Puerto Rico, India, Philippines, and Jamaica. Recent research results have shown a high level of student achievement when using the Educosoft LMS for undergraduate mathematics courses [4].

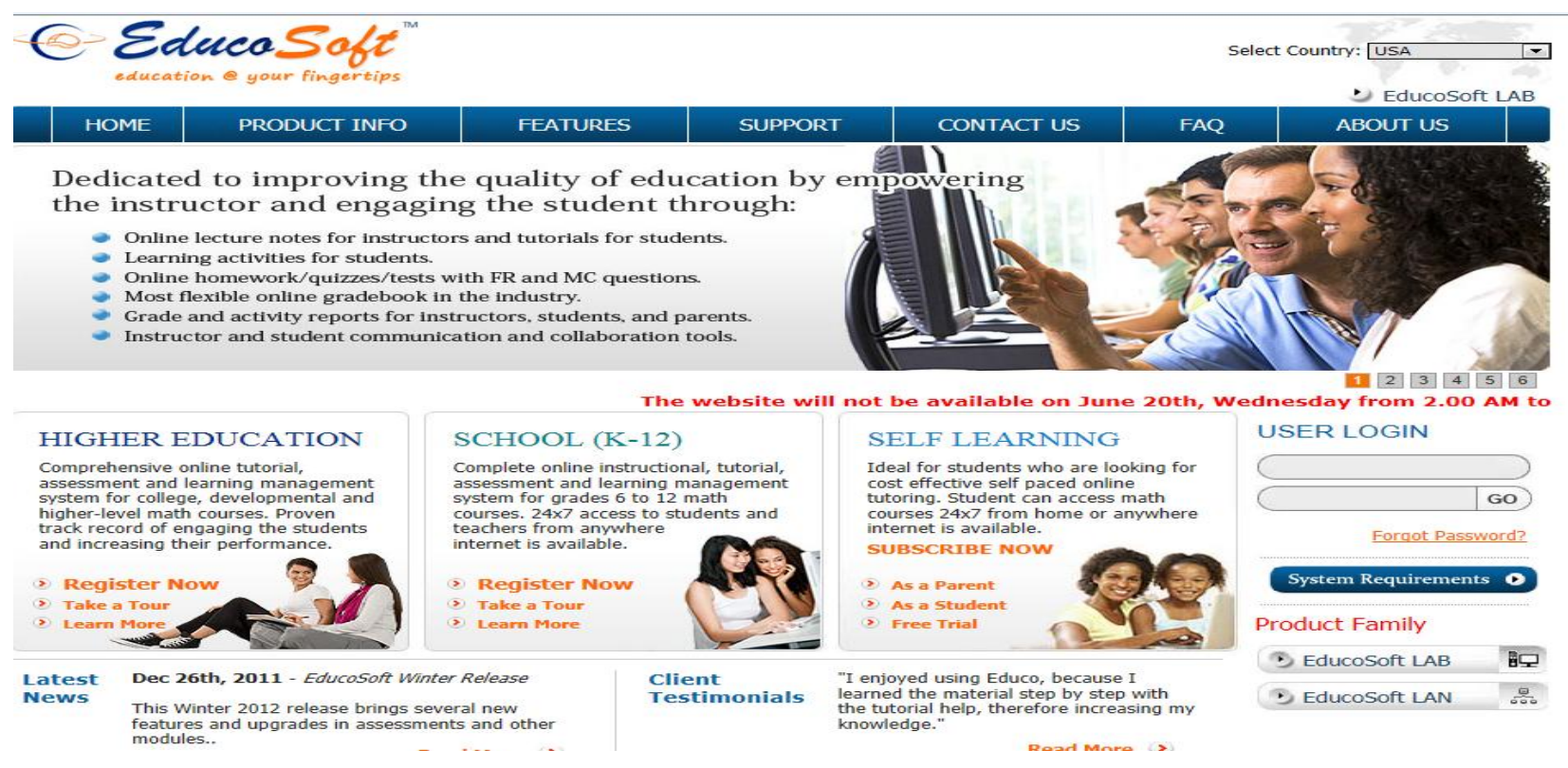

Figure 1. Learning Management System-Educosoft

\section{OBJECTIVES OF THE STUDY}

The objectives of the study are:

1. To determine the efficiency of the Learning Management System (LMS) in regards to the academic performance of first-year college-level students with poor math skills who expect to obtain a baccalaureate degree in the areas of Health, Social Sciences, Design, Education, Business, Engineering, Natural Sciences and Technology. 


\section{Issues in Information Systems \\ Volume 14, Issue 2, pp.253-261, 2013}

2. To determine the impact of the experimental approach on students' final grades and retention in the course, as compared to the student's final grades and retention in a course which utilized the traditional teaching approach.

\section{RESEARCH METHODOLOGY}

The objective of this study was to investigate the effects of using a Learning Management System (LMS) and compare it to the traditional math teaching method for first-year college students. The dependant variable for this study was the academic achievement of the students, while the independent variable was the teaching strategy.

\section{Sample}

The sample consisted of 1,045 first-year college students at a private university; 491 were in the control group and 554 were in the experimental group. The students chosen for the control group were those who obtained 550 or higher on the College Board mathematical reasoning exam, which is an entrance exam for college admissions in Puerto Rico. The students in the experimental group were those scoring 490 or less on the same exam. In other words, indicative of students' test scores, students in control group had a dual initial advantage over the experimental group, as they had less content to cover and a better initial level of mathematical understanding. The students in the study were part of a total population who were registered in the freshmen math course during their first semester of college. These students were from a diverse pool that expected to obtain their baccalaureate degree in Health, Social Sciences, Design, Education, Business, Engineering, and Science and Technology. Their academic performance and retention was analyzed utilizing final grades in the course. The students in the experimental group were exposed to the structured instructional approaches using Learning Management System (LMS) of an e-learning portal www.educosoft.com, while the students in the control group were subjected to traditional teaching methods.

\section{Research Instrument}

To measure academic performance, the final course grades were obtained for each student. The data was gathered from the official university database system. To measure the final grade of the experimental group, several categories for all students were standardized. The categories were: Assignments $=10 \%$, Quizzes $=10 \%$, Exams 1, 2 and $3=25 \%$, Midterm $=20 \%$, Tutorial Time $=10 \%$, Attendance $=5 \%$, Departmental Final Exam $=20 \%$. To measure the final grade of the control group, the final grade was not subject to standardization by categories; however, they had two departmental exams (a midterm and a final) and other activities (partial exams and assignments) as indicated in the course syllabus.

\section{Faculty Training}

The professors participating in the experimental group had to go through two phases of training before teaching the course. In the first phase, the professors were placed in a training class as students and subjected to treatment that replicated the same experience their students would go through while taking their classes. The treatment included; a one day orientation, six weeks of online engagements through weekly homework assignments with related tutorial as pre-requisites, one quiz which required the completion homework as a pre-requisite, two major tests online, and a final supervised test. In the second phase, professors were trained how to use the Educosoft Learning Management System for performing the role as a teacher. The second phase training included; creating and managing the online grade book, creating homework and quizzes, creating announcement and surveys, and how to use reports to motivate students. All instructors in the experimental group were required to take this training.

\section{Control Group}

The materials used for the control group were the course syllabus, the hard copy of the textbook, exercises assigned by the professor, and two departmental exams (a midterm and a final) and partial exams. Each departmental exam had a value of $20 \%$ of the final grade. Other partial exams were administered by the professors and were indicated in the course syllabus, which was handed out at the beginning of the course. The departmental exams were multiple choice exams. Before each departmental exam, a review was offered to the students in the library. Additionally, each student took the course in the classroom for a period of three hours per week in a traditional classroom setting. 


\section{Issues in Information Systems}

Volume 14, Issue 2, pp.253-261, 2013

\section{Experimental Group}

The students from the experimental group were provided orientation about completing their online assignments, accessing the e-book, and using the Educosoft LMS. This orientation was scheduled in the mathematics laboratory during the first weeks of classes. Additionally, all sections (classes) in this group were required to follow a master lesson plan, prepared jointly by the participating instructors. As per this plan, all instructors covered the same material in a week, and students had to complete the same online assignments based on class discussions. The use of structured instructional approaches delivered using the Educosoft LMS is considered as the independent variable in this study. Each class met face-to-face for three hours a week, and the rest of the time, students were completing learning and assignments online and monitored by their instructors online. In addition to class hours, the student went to the math laboratory two (2) hours per week to complete activities, tutorial, assignments, and quizzes. The students also had the opportunity to receive help in a Student Support Center, if they could not finish the activities or could not perform these activities online at home. The two major exams were administered by the laboratory professor in a controlled environment that required a password entry code. All activities and exams included both multiple choice and open ended responses.

\section{Learning Cycle (Sharma Model)}

The Learning Cycle Model for Educosoft developed by Dr. Man Sharma, Professor Emeritus of Clark Atlanta University, includes a complete diagnosis, learning, assessment, and reporting activities for each and every topic of the course [21]. As depicted in Figure 2, this cycle includes; 1) diagnoses as part of tutorials, 2) learning through tutorials, 3) re-enforcement through examples with built-in solutions, 4) self- assessment through practice tests, each with several sets of similar questions with solutions after submitting, 5) online homework and quizzes, and 6) provision to see progress reports. The tutorials also included videos and the e-book to accommodate different learning styles. All of the help for students were provided in the tutorials or through solutions provided after submitting assignments.

Once the students have completed the homework assignments with a score of $75 \%$ or more, they are then permitted to take the quiz or exam, which is given in the math laboratory in a controlled environment and supervised by the laboratory professor. As the Learning Cycle for each topic is completed, grades are reported automatically in the online grade book.

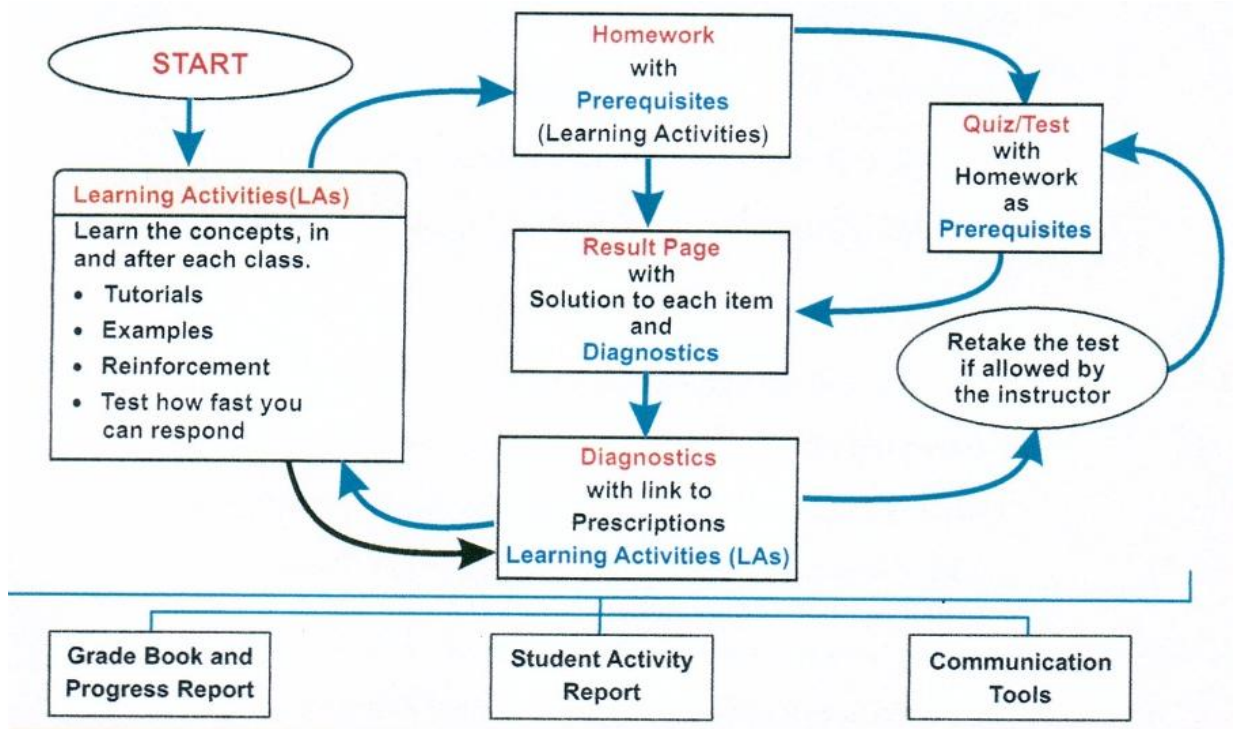

Figure 2. Learning Cycle (Sharma Model) 


\section{Issues in Information Systems \\ Volume 14, Issue 2, pp.253-261, 2013}

RESULTS

To compare performance of the control group to the experimental group, it was necessary to exclude 231 students who obtained grades of I, W, WF, and WN. These were students who withdrew from the course or received an incomplete because they did not take the final exam. As indicated in Table 2, the mean in grades for the control group was 2.80, and the experimental group was 3.05, as illustrated in Table 1. That indicates in general, that the students in the experimental group had a better outcome, in spite of the fact that they had more course material to cover and lower scores on the College Board Entrance Exam than the control group. On the other hand, it can be pointed out that there are mayor differences between the grades of the students in the experimental group as compared to the control group. The variance from Table 1 in the experimental group was 2.10, while Table 2 notes the control group variance was 1.87 .

Table 1. Descriptive Statistics of Experimental Group Final Grades

\begin{tabular}{|c|c|c|c|c|c|c|c|c|}
\hline & $\mathrm{N}$ & Range & Minimum & Maximum & \multicolumn{2}{|c|}{ Mean } & Std. Deviation & Variance \\
\hline & Statistic & Statistic & Statistic & Statistic & Statistic & Std. Error & Statistic & Statistic \\
\hline $\begin{array}{l}\text { Experimental } \\
\text { Group }\end{array}$ & 439 & 4.00 & 1.00 & 5.00 & 3.0501 & .06928 & 1.45158 & 2.107 \\
\hline
\end{tabular}

Table 2. Descriptive Statistics of Control Group Final Grades

\begin{tabular}{|c|c|c|c|c|c|c|c|c|}
\hline & $\mathrm{N}$ & Range & Minimum & Maximum & \multicolumn{2}{|c|}{ Mean } & Std. Deviation & Variance \\
\hline & Statistic & Statistic & Statistic & Statistic & Statistic & Std. Error & Statistic & Statistic \\
\hline Control Group & 375 & 4.00 & 1.00 & 5.00 & 2.8080 & .07076 & 1.37021 & 1.877 \\
\hline
\end{tabular}

Thus a significant difference was found in the academic performance of the students in the experimental group as compared to the control group, as the t Stat was -2.43 (Table 3) and it is less than the t critical two-tail, which was 1.96 (Table 3). This shows the rejection that there was no difference between both means of both the control and experimental group. In other words, data from Table 3 confirmed that the p-value was 0.015 and it is less than the significance level of 0.05 ; hence, there is a significant difference between the two groups.

Table 3. Inferential Statistics ( t-Test) of Final Grades

\begin{tabular}{|l|c|}
\hline & \\
\hline Hypothesized Mean Difference & 0 \\
\hline df & 812 \\
\hline $\mathrm{t}$ Stat & -2.43386742 \\
\hline $\mathrm{P}(\mathrm{T}<=\mathrm{t})$ one-tail & 0.007576562 \\
\hline $\mathrm{t}$ Critical one-tail & 1.646732346 \\
\hline $\mathrm{P}(\mathrm{T}<=\mathrm{t})$ two-tail & 0.015153124 \\
\hline $\mathrm{t}$ Critical two-tail & 1.962889744 \\
\hline
\end{tabular}

The results of the final grades distribution, which can be found in Figure 3 also illustrated that $50 \%$ of the students who participated in the experimental group passed the course with grades of A, B or C as compared to $46 \%$ in the control group. In the experimental group, 50\% obtained unsatisfactory grades of D and $\mathrm{F}$ and codes of I, W, WF, and WN as compared to 54\% in the control group. A code of I stands for Incomplete and occurs when the student took the course, but did not take the final exam. With a valid excuse, the student is allowed to complete the final 


\section{Issues in Information Systems \\ Volume 14, Issue 2, pp.253-261, 2013}

exam at a later date. Additionally, the code of $\mathrm{W}$ stands for a Withdrawal and indicates that the student withdrew from the course. A code of WF represents a Withdrawal from the course with failing status. A code of WN represents a Withdraw from the class for not attending. Note that there were $4 \%$ more students in the experimental group who passed the course. Furthermore, the analysis showed that the experimental group had $6 \%$ more students with a grade of A, $4 \%$ more who obtained B, $1 \%$ less obtained an F, and $4 \%$ less obtained a $\mathrm{W}$. This indicates better performance of the experimental group in all measureable parameters.

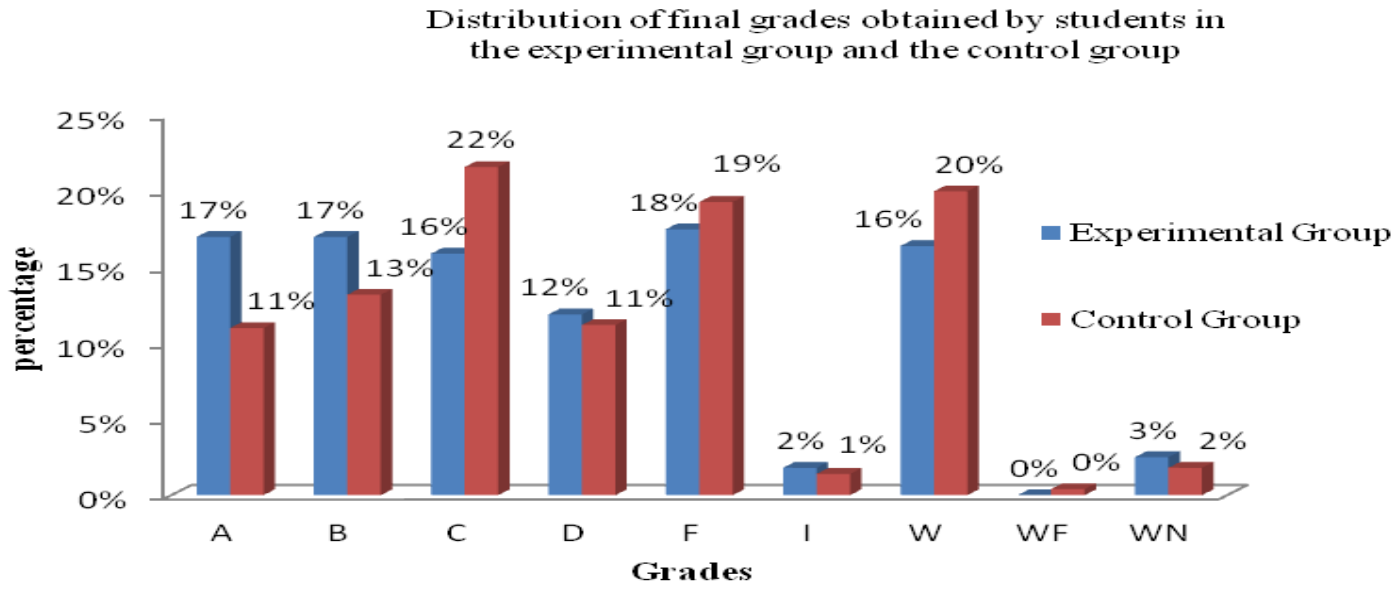

Figure 3. Distribution of Final Grades

Noteworthy to mention, students in the experimental group dedicated approximately 59 hours utilizing the Educosoft Learning Management System, of which 22 hours were on tutoring, 9 hours on exams and quizzes, 9 hours in practice, and 19 hours of homework assignments (Table 4).

Table 4. Descriptive Statistics of Experimental Group Dedicated Time

\begin{tabular}{|c|c|c|c|c|c|c|c|c|c|}
\hline & $\mathrm{N}$ & Range & Minimum & Maximum & Sum & \multicolumn{2}{|c|}{ Mean } & Std. Deviation & Variance \\
\hline & Statistic & Statistic & Statistic & Statistic & Statistic & Statistic & Std. Error & Statistic & Statistic \\
\hline Tutorial & 439 & 130.30 & .30 & 130.60 & 9050.20 & 22.0200 & .85518 & 17.33709 & 300.575 \\
\hline Test & 439 & 19.20 & .00 & 19.20 & 3688.40 & 8.9742 & .16216 & 3.28750 & 10.808 \\
\hline Practice & 439 & 37.60 & .00 & 37.60 & 3641.70 & 8.8606 & .35510 & 7.19902 & 51.826 \\
\hline Homework & 439 & 70.00 & .00 & 70.00 & 7796.70 & 18.9701 & .46744 & 9.47651 & 89.804 \\
\hline Total & 439 & 191.10 & 2.50 & 193.60 & 24167.20 & 58.8010 & 1.40258 & 28.43475 & 808.535 \\
\hline
\end{tabular}

Additionally, a Boxplot of Students' Final Grades was analyzed. The smallest value was 1 (F) and the highest value was 5 (A) for both the control and experimental groups. The results showed that for the control group, the first, second, and third quartiles are 1,3, and 4 respectively. However, the first, second, and third quartiles were 2, 3, and 4 respectively for the experimental group. Thus, the experimental group had a higher second quartile value than the control group. Furthermore, the Boxplot revealed that the experimental group had more consistency in grades, while the control group had a greater variability (Figure 4). 


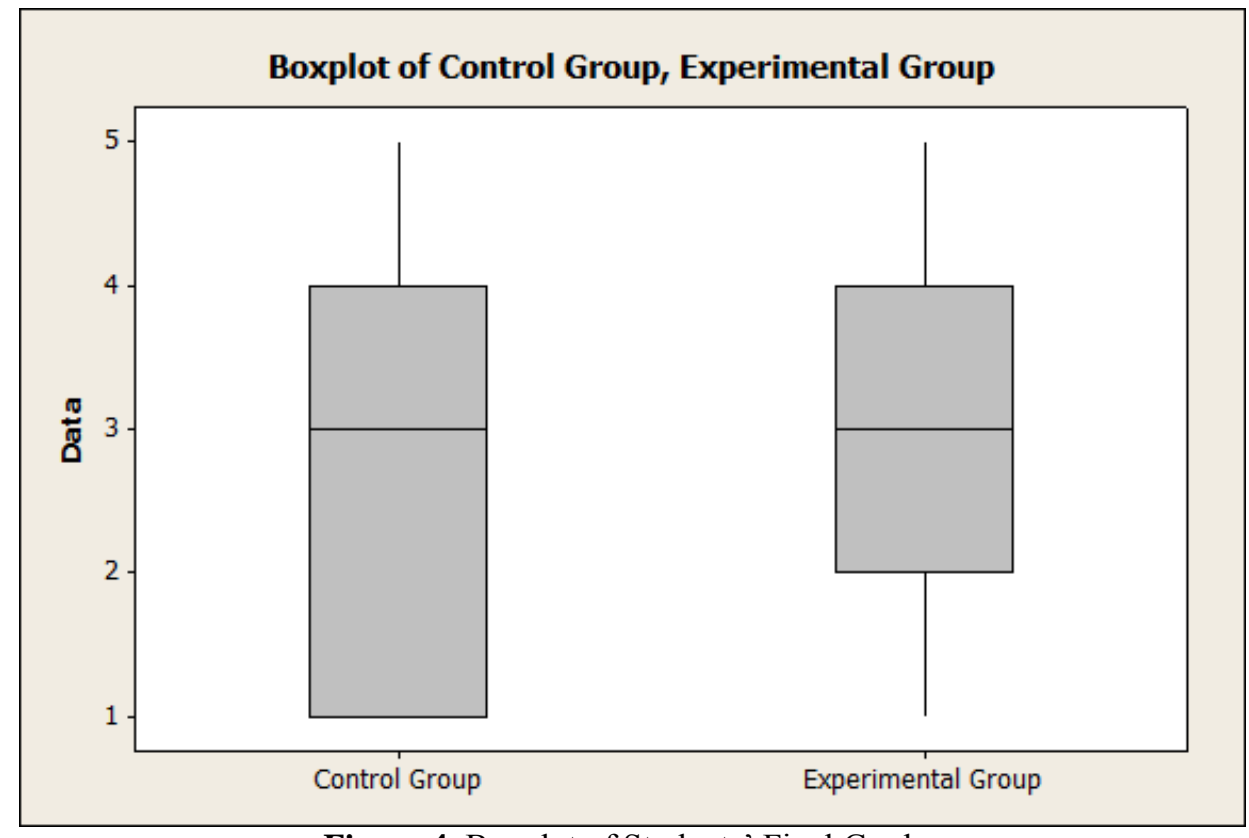

Figure 4. Boxplot of Students' Final Grades

\section{CONCLUSIONS}

The results of this research revealed the effectiveness of the use of structured instructional approaches using the Educosoft Learning Management System at 95\% level of confidence of the statistical test. The resulting P-value of 0.015 demonstrates that there is a significant difference when this type of technology (LMS) is used as opposed to the traditional method of teaching math. Although the students in the experimental group were given more content to learn and had lower college entrance exam scores in math than the control group, these students elicited higher academic performance in the same time period when compared to the traditional teaching method. The fact that $6 \%$ more students earned a grade of A, 4\% more B's, a 1\% less F's and 4\% less W's establishes that not only was student performance higher, even the retention in the course was significantly more in the experimental groups, as compared to the control group. With the use of this technology, retention increased $4 \%$ as indicated by a $50 \%$ course passing rate obtained by students who received grades of A, B, and C in the experimental group, as compared to only $46 \%$ in the control group in this math course for first-year college students. Thus, the results of this study validate that structured instructional approaches using the Educosoft Learning Management System is an effective tool when teaching first-year math courses for students aspiring to obtain bachelor degrees in Health, Social Sciences, Design, Education, Business, Engineering, and Science and Technology.

\section{REFERENCES}

1. Allen I. E., and Seaman J., Staying the course-online education in the United States, 2008, Sloan Consortium, Needham, MA, 2008. Available at http://www.sloan-c.org/ publications/survey/index.asp

2. Bersin J., Howard C., and Leonard K. O, Learning Management Systems 2010: Facts, Practical Analysis, Trends and Vendor Profiles, Bersin \& Associates, Oakland,CA, 2009.

3. Camm J., O.R. in the classroom - Get real! OR/MS Today 34 (2007), pp. 34-37.

4. Colón-Berríos, A. (2009). El efecto del uso del sistema de enseñanza Educosoft durante el proceso enseñanza y aprendizaje en el aprovechamiento académico y la actitud hacia las matemáticas (Doctoral dissertation). [The effect of the use of the Educosoft teaching and learning system in student academic achievement and attitudes towards mathematics]. Available at ProQuest UMI Number: 3397442

5. Faulin J., Juan A., Fonseca P., Pla L.M., and Rodriguez S. V., Learning Operations Research online: Benefits, challenges, and experiences, Int. J. Simul. Process. Model. 5(1) (2009), pp. 42-53.

6. Federal Reserve Bank of New York (2012). Report on the competitiveness of Puerto Rico's economy. Available at http://www.newyorkfed.org/regional/puertorico/report.pdf 


\section{Issues in Information Systems}

Volume 14, Issue 2, pp.253-261, 2013

7. Hardin J. and Ellington A., Using multimedia to facilitate software instruction in an introductory modeling course, INFORMS Trans. Educ. 5(2) (2005), pp. 9-16. Available at http://ite.pubs.informs.org/

8. Hanyshek, E., Peterson, P.\&Woesmann, L. (2012). Achievement growth: International and U.S. State trends in student performance. Harvard's Program of Education Policy and Governance \& Education Next. Available at http://www.hks.harvard.edu/pepg/PDF/Papers/PEPG12-03_CatchingUp.pdf

9. Juan A.A., Steegmann C., Huertas A., Martinez M.J. and Simosa J. (2011). Teaching mathematics online in the European Area of Higher Education: an instructor point of view. International Journal of Mathematical Education in Science and Technology, 42(2), 142-153.

10. Kersaint, G., Horton, B., Stohl, H., \& Garofalo, J. (2003). Technology beliefs and practices of mathematics education faculty. Journal of Technology and Teacher Education, 11(4), 549-577.

11. Keynes, H., \& Olson, A. (2001). Professional development for changing undergraduate mathematics instruction. In D. Holton (Ed.), The Teaching and Learning of Mathematics at the University Level: An ICMI Study (pp. 113-126). Dordrecht: Kluwer.

12. Kochar K.S, (1992). Methods and Techniques of Teaching. Sterling publishers private Limited.

13. Leon L., Przasnyski Z. and Seal K., Teaching OR/MS to net-gens: A paradigm gap, OR/MS Today 35 (2008), pp. 10-11.

14. Mishra R.C (2005). Teaching of Information. APH Publishing Corporation, New Delhi. P. 66-298.

15. Nagy A., The impact of e-learning, in E-Content: Technologies and Perspectives for the European Market, P.A. Bruck, A. Buchholz, Z. Karssen, and A. Zerfass, eds., Springer-Verlag, Berlin, 2005, pp. 79-96.

16. Pandey V.C (2001). Digital Technologies and Teaching Strategies. Isha Books Publisher, Delhi. P.94-168.

17. Oates G., Integrated Technology in Undergraduate Mathematics: Issues of Assessments. The Electronic Journal of Mathematics and Technology, 4(2)(2009), pp. 163-174

18. Oates G., Sustaining Integrated Technology in Undergraduate Mathematics: The International Journal of Mathematics Education in Science and Technology, 42(15)(2011), pp. 710-721

19. Pelgrum W.J. \& Nancy L. (2003). ICT in Education Around the World: Trends, Problems and Prospects. International Institute of Educational Planning, UNESCO. Paris. P. 17-122.

20. Sfdar A.,Yousuf M.I, Parveen Q. and Behlol M.G. Effectiveness of Information and Communication Technology (ICT) in Teaching mathematics at Secondary Level. International Journal of Academic Research, 3(5) (2011), pp. 67-72.

21. Sharma, M. (2013) www.educosoft.com. Educosoft learning pedagogy. Available at https://www.educosoft.com/Home/pdf/US\%20Self\%20Learning.pdf

22. Simonson M., Smaldino S., M. Albright, and S. Zvacek, Teaching and Learning at a Distance: Foundations of Distance Education, Prentice-Hall, Upper Saddle River, NJ, 2008.

23. U.S. Department of Education, National Center for Education Statistics. (2012). Digest of Education Statistics, 2011 (NCES 2012-001), Table 153. Available at http://nces.ed.gov/fastfacts/display.asp?id=171

24. Woolfolk A. (2004). Educational Psychology. 9th Edition, published by Pearson Education (Pvt.) Limited,Delhi, India. 